Document downloaded from:

http://hdl.handle.net/10251/60649

This paper must be cited as:

Fernández Domene, RM.; Sánchez Tovar, R.; García Antón, J. (2014). Passive Behavior and Passivity Breakdown of AISI 304 in LiBr Solutions through Scanning Electrochemical Microscopy. Journal of The Electrochemical Society. 161(12):565-572. doi:00134651/2014/161(12)/C565/8/\$31.00.

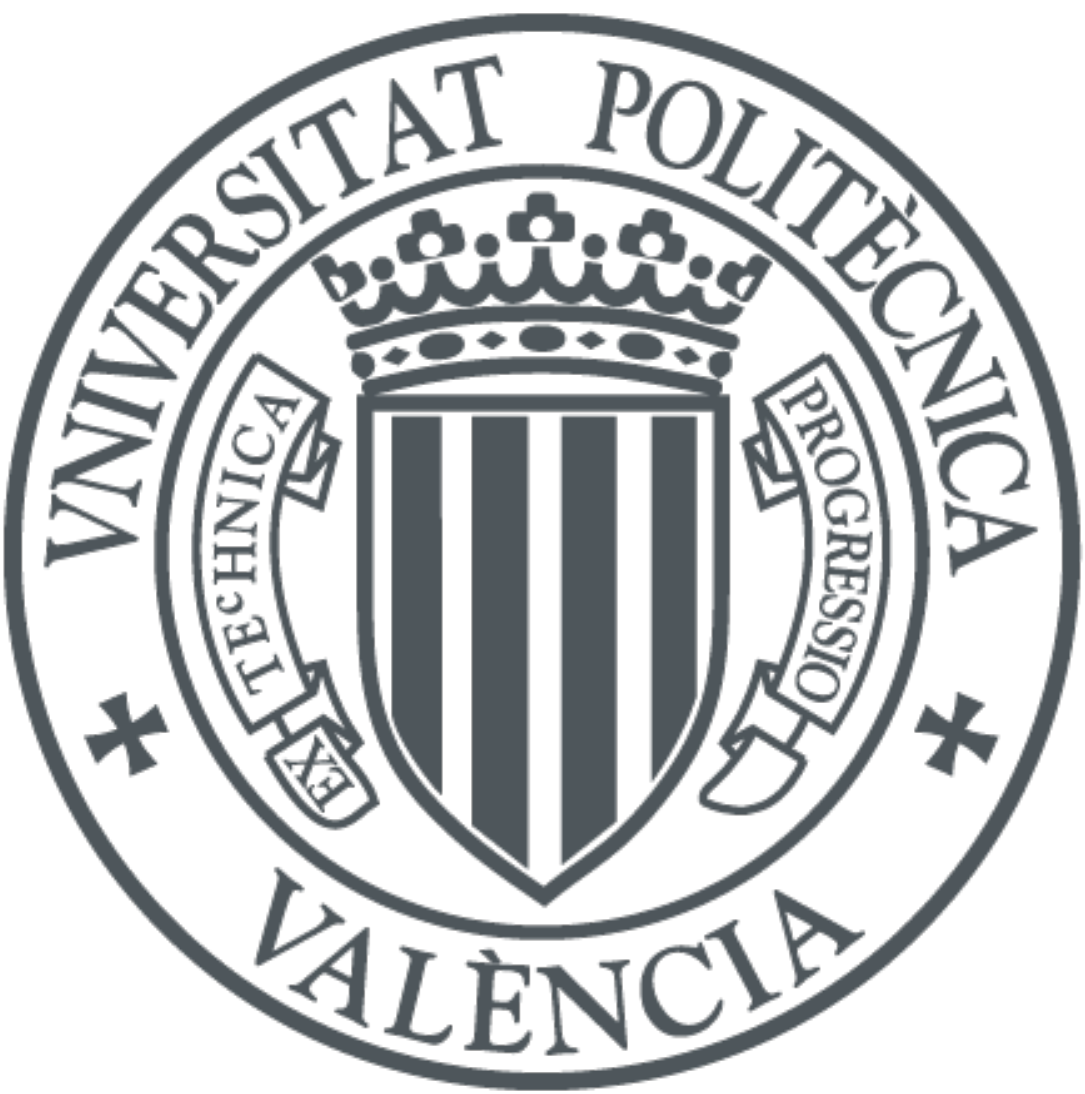

The final publication is available at

http://dx.doi.org/10.1149/2.1051412jes

Copyright Electrochemical Society

Additional Information 


\section{Passive Behavior and Passivity Breakdown of AISI 304 in LiBr Solutions through Scanning Electrochemical Microscopy}

4

\section{R. M. Fernandez-Domene, R. Sánchez-Tovar, and J. García-Antón ${ }^{z}$}

Ingeniería Electroquímica y Corrosión (IEC), Departamento de Ingeniería Química y Nuclear, ETSI Industriales, Universitat Politècnica de València, Camino de Vera s/n, 46022 Valencia, Spain

${ }^{\mathrm{z}}$ E-mail: jgarciaa@iqn.upv.es

1 The passive behavior and passivity breakdown of AISI 304 stainless steel in $\mathrm{LiBr}$ solutions has been investigated by means of scanning electrochemical microscopy (SECM). The sample generation - tip collection (SG-TC) mode was used to operate the SECM and the tip potential was biased to detect the electroactive species. The evolution of the current at the ultramicroelectrode tip with the applied potential within the passive range was followed at different $\mathrm{LiBr}$ concentrations. Results show that the absolute value of the current at the tip increases with the applied potential. Additionally, SECM was also used to detect stable pits formed on the stainless steel surface in a $0.2 \mathrm{M} \mathrm{LiBr}$ solution. The results show clear evidence of the presence of high amounts of other reducible species (metal cations) apart from oxygen. Also, the dish-shape morphology of the pits observed using Confocal Laser Scanning Microscopy will be discussed in relation to the kinetics of the reactions observed using SECM.

Manuscript submitted April 22, 2014; revised manuscript received September 5, 2014. Published xx xx, xxxx. 


\section{INTRODUCTION}

Stainless steel (SS) is a generic name commonly used for the group of iron-based alloys which are the most widely known metallic materials [1-3]. One of the main characteristics of SS is their resistance to corrosion in many environments, which is provided by a very thin and protective surface oxide film, known as passive film. It is generally accepted that passive films formed on SS have a duplex structure which consists of an inner region rich in chromium and an outer region rich in iron [4-9]. Austenitic SS are the most common and familiar types of SS [2]. Among austenitic SS, type 304 SS contains approximately 18 wt. $\%$ of chromium and 8 wt. $\%$ of nickel and is widely used in chemical processing equipment, for food, dairy, and beverage industries, for heat exchangers and in the milder chemicals.

Pitting corrosion of passive metals is considered to be more dangerous than uniform corrosion, since it is more difficult to detect, predict and design against [10]. Localized breakdown of passive films leads to an enhancement of metal dissolution at the site of the pit due to the formation of a galvanic cell between the pit (anode) and the intact passive film (cathode). Therefore, pitting corrosion may result in perforation of a pipe or in structural failure [2].

Scanning Electrochemical Microscopy (SECM) has become a powerful technique for quantitative investigations of corrosion processes, including the study of pitting corrosion and other localized degradation processes [11-28]. SECM involves the use of a mobile ultramicroelectrode (UME) probe of micrometer dimension to investigate the activity and/or topography of an interface on a localized scale [29]. One of the modes of 
52 SECM operation is the substrate generation/tip collection (SG/TC) mode, in which the

53 substrate under study acts to generate species that are measured at the UME tip, which

54 is held at a potential sufficient for a redox reaction to occur. SECM is an ideal tool for

55 the investigation of local corrosion phenomena since it permits the possibility of

56 precisely positioning the small UME tip close to the object under investigation, the

57 active pit, in contrast to conventional methods frequently used to study pitting corrosion

58 of passive metals, such as potentiodynamic polarization curves or electrochemical

59 impedance spectroscopy (EIS).

60

61 The dissolution and pitting corrosion of iron and carbon steels [14, 22, 23, 27], as well

62 as of stainless steels $[11,15,17-20,24,28]$ have been investigated by SECM in several

63 electrolytes containing $\mathrm{Cl}^{-}$anions. However, studies on pitting corrosion of stainless

64 steels in the presence of $\mathrm{Br}^{-}$anions using SECM have not been found in the literature.

65 Therefore, the aim of this study is to investigate the passive behavior and passivity

66 breakdown of an austenitic stainless steel (AISI 304) in $\mathrm{Br}^{-}$containing solutions by

67 means of SECM and Confocal Laser Scanning Microscopy.

68

69

2. EXPERIMENTAL PROCEDURE

70

\subsection{Material and electrolyte}

72

73 The material tested was AISI 304 stainless steel (SS) (0.05 wt.\% C, 18 wt.\% Cr, 10 74 wt.\% Ni, 0.4 wt.\% Si, 0.1 wt.\% N, Bal. Fe). AISI 304 SS electrodes were cylindrically

75 shaped and covered with a polytetrafluoroethylene (PTFE) coating, to expose an area of $760.5 \mathrm{~cm}^{2}$ to the test solution. All specimens were wet abraded from 200 to $4000 \mathrm{SiC}$ grit, 
and finally rinsed with distilled water and air-dried. AISI 304 SS electrodes were tested in two different naturally-aerated $\mathrm{LiBr}$ solutions: $0.2 \mathrm{M}$ and $0.6 \mathrm{M}$, at a constant temperature of $25^{\circ} \mathrm{C}$.

80

\subsection{Potentiodynamic polarization curves}

82

83 Cyclic potentiodynamic polarization curves of AISI 304 SS in the LiBr solutions were determined using a SOLARTRON 1287 potentiostat. The curves were repeated at least three times in order to verify reproducibility. The working electrode potential was measured vs. a silver-silver chloride $(\mathrm{Ag} / \mathrm{AgCl} 3 \mathrm{M} \mathrm{KCl})$ reference electrode. The auxiliary electrode was a platinum wire. Before the tests, the specimen potential was reduced to $-0.4 \mathrm{~V}_{\mathrm{Ag} / \mathrm{AgCl}}$ in order to create reproducible initial conditions. Then, the electrode potential was scanned from $-0.4 \mathrm{~V}_{\mathrm{Ag} / \mathrm{AgCl}}$ in the positive direction at $0.5 \mathrm{mV} \mathrm{s}^{-1}$. When the current density reached $10 \mathrm{~mA} \mathrm{~cm}{ }^{-2}$, the potential scan was reversed in order to evaluate the repassivation tendency.

92

93 From the $E$-log $i$ plot, the corrosion potential $\left(E_{\text {corr }}\right)$ and corrosion current density $\left(i_{\text {corr }}\right)$ were obtained. The pitting potential $\left(E_{p}\right)$ was evaluated using a criteria previously used in other studies [30], once the rapid and stable increase of the anodic current density occurs. The repassivation potential values $\left(E_{r p}\right)$ were taken at the crossing between the backward scan and the forward scan [31]. Passive and repassivation current densities $\left(i_{p}\right.$ and $i_{r p}$, respectively) were also obtained, being $i_{\mathrm{p}}$ the current density in the passive domain and $i_{r p}$ the current density at $E_{r p}$.

\subsection{SECM measurements}


103 SECM tests were performed using a Sensolytics device connected to an Autolab

104 AUT84192 bipotentiostat. A platinum ultramicroelectrode (UME) of $25 \mu \mathrm{m}$ in diameter

105 (the outer glass shield was $1.5 \mathrm{~mm}$ in diameter) was used as the SECM tip. Oxygen was

106 used as the electrochemical mediator at the tip. The cyclic voltammogram was recorded

107 at a scan rate of $50 \mathrm{mV} \mathrm{s}^{-1}$ from $0 \mathrm{~V}_{\mathrm{Ag} / \mathrm{AgCl}}$ to $-1.2 \mathrm{~V}_{\mathrm{Ag} / \mathrm{AgCl}}$. Figure 1 shows the cyclic

108 voltammogram of $\mathrm{O}_{2}$ in the $0.2 \mathrm{M} \mathrm{LiBr}$ solution using the $25 \mu \mathrm{m}$ platinum UME. A

109 wide current plateau can be observed at potential values between $-0.5 \mathrm{~V} \mathrm{Ag} / \mathrm{AgCl}$ and -1

$110 \mathrm{~V}_{\mathrm{Ag} / \mathrm{AgCl}}$, approximately, corresponding to the oxygen reduction reaction:

$$
\mathrm{O}_{2}+2 \mathrm{H}_{2} \mathrm{O}+4 \mathrm{e}^{-} \rightarrow 4 \mathrm{OH}^{-}
$$

114 The curve displayed in Figure 1 was used to choose the potential of the UME tip, which

115 was set at $-0.7 \mathrm{~V}_{\mathrm{Ag} / \mathrm{AgCl}}$ to enable the diffusion-limited reduction of oxygen at the tip.

117 To study the influence of the applied potential on the passive behavior of AISI 304 SS,

118 passive films were formed on its surface imposing different potentials within the 119 passive range $\left(0.0,0.1\right.$ and $\left.0.2 \mathrm{~V}_{\mathrm{Ag} / \mathrm{AgCl}}\right)$ for 1 hour.

121 The reduction of oxygen on the microelectrode was used to establish the height of the tip over the AISI 304 SS sample. After passive film formation, approach curves representing Current (I) vs. Distance between the UME tip and the surface of the sample

124 (Z) were performed to select the best height of the UME tip. As an example, Figure 2 125 shows an approach curve for the tip polarized at $-0.7 \mathrm{~V}_{\mathrm{Ag} / \mathrm{AgCl}}$ with the sample potential set at $0.0 \mathrm{~V}$ in the $0.2 \mathrm{M} \mathrm{LiBr}$ solution. The zero position of the tip, that is, the point 
127 where the approach curves began, was an arbitrary position such that the influence of

128 the specimen on the probe response was not significant. From this zero position the

129 UME was moved down towards the sample and it stopped when the tip current reached

$13075 \%$ of the initial value in the bulk solution [25]. In order to prevent the tip from

131 scratching the AISI 304 SS surface, due to roughness or small tilt of the sample, the

132 distance between the UME and the substrate surface was afterwards increased by $5 \mu \mathrm{m}$.

133 This increase in the tip-substrate distance by $5 \mu \mathrm{m}$ resulted in an increase in the tip

134 current by $8.33 \%$, in absolute value. Then, SECM scans were obtained by positioning

135 the UME tip directly above and perpendicular to the sample and scanning the surface at 136 steps of $250 \mu \mathrm{m}$ in the $\mathrm{X}$ and $\mathrm{Y}$ directions. The scanned dimensions were $2000 \mu \mathrm{m} \times$ $1372000 \mu \mathrm{m}$ and the scan rate was $50 \mu \mathrm{m} \mathrm{s}^{-1}$.

139 To study the initiation and formation of stable pits on the surface of the AISI 304 SS in

140 the $0.2 \mathrm{M} \mathrm{LiBr}$ solution, the sample was subsequently biased at $0.45 \mathrm{~V}_{\mathrm{Ag} / \mathrm{AgCl}}$, a 141 potential close to the pitting potential. After the appearance of the first stable pit, 142 different line scans were performed at different times by shifting the UME tip $3000 \mu \mathrm{m}$

143 along the $\mathrm{X}$ direction passing just above the pit, at steps of $250 \mu \mathrm{m}$. Although the step

144 size was significantly bigger than the tip diameter, this approach is acceptable in this 145 case because the aim of the present work is not to resolve the surface to evidence 146 precursor sites for pit nucleation, but to follow the propagation stages of a stable pit

147 once nucleated. The tip potential remained set at $-0.7 \mathrm{~V}_{\mathrm{Ag} / \mathrm{AgCl}}$ to detect the electroactive 148 species (metal cations) released from the localized corrosion site by reducing them at 149 the UME tip, thus obtaining a cathodic current related to the activity within the pit.

150 Using this mode of SECM operation, called sample generation - tip collection (SG-TC), 151 the use of electrochemical mediators (i.e., an oxidizable/reducible species) that could 
152 interact with the substrate, such as the redox couple $\mathrm{I}^{-} / \mathrm{I}_{3}{ }^{-}$, is avoided, thus eliminating

153 their interference with the corrosion reactions [11, 25, 29]. A 3D map of the surface

154 around the pit was also obtained through scanning the surface at steps of $500 \mu \mathrm{m}$ in the

$155 \mathrm{X}$ and $\mathrm{Y}$ directions. The scanned dimensions were $3000 \mu \mathrm{m} \times 2000 \mu \mathrm{m}$ in $\mathrm{X}$ and $\mathrm{Y}$,

156 respectively, with a scan rate of $50 \mu \mathrm{m} \mathrm{s}^{-1}$.

157

158 After studying the formation and growth of a stable pit on the AISI 304 SS, the sample 159 polarization was stopped to study pit repassivation at open circuit potential. Line scans 160 and a 3D map of the surface were also obtained, following the same procedure 161 explained above.

162

\subsection{Confocal Laser Scanning Microscope measurements}

After potentiodynamic polarization curves, the AISI 304 SS samples were rinsed and examined with a Confocal Laser Scanning Microscope (CLSM) Olympus LEXT OLS3100, which uses the LEXT OLS 6.0.3 software. The CLSM uses a Laser Diode with a wavelength of $408 \mathrm{~nm}$, an outstanding horizontal resolution of $0.22 \mu \mathrm{m}$, vertical resolution of $0.01 \mu \mathrm{m}$ (z-axis), and a magnification range from 120x to 14400x.

170

171 The morphology of the pit formed on the AISI 304 SS electrode after the SECM 172 measurements was also examined using the CLSM. The average pit radius and pit depth 173 were quantified with the CLSM.

\section{RESULTS AND DISCUSSION}


179 Table 1 shows the parameters determined from polarization curves (Figure 3) at two 180 different $\mathrm{LiBr}$ concentrations: $0.2 \mathrm{M}$ and $0.6 \mathrm{M}$. As it can be seen in Table 1, an increase 181 in $\mathrm{LiBr}$ concentration from $0.2 \mathrm{M}$ to $0.6 \mathrm{M}$ slightly shifts corrosion potentials to more 182 active values and enhances corrosion current densities.

183 Polarization curves also provide information about the pitting, passivation and 184 repassivation behavior of the material. AISI 304 is susceptible to pitting corrosion since 185 bromides are very aggressive ions that promote SS passive film breakdown [30, 32, 33].

186 The lowest $\mathrm{E}_{\mathrm{p}}$ determined in the $0.6 \mathrm{M} \mathrm{LiBr}$ solution indicates that bromides promote a 187 decrease in the pitting corrosion resistance and, consequently, the breakdown of the 188 passive film and the initiation of pits occur at less positive potentials.

189 Table 1 shows that passive current densities are higher in the LiBr solution that 190 contains more bromides. Table 1 also shows that repassivation current densities 191 obtained in both $\mathrm{LiBr}$ solutions are statistically the same. Since $i_{r p}$ is a measure of the 192 ability of materials to repassivate and, hence, of the extent of propagation once 193 corrosion has initiated, the previous results indicate that the ability of AISI 304 to 194 repassivate is essentially the same in both $\mathrm{LiBr}$ solutions. Additionally, $E_{\mathrm{rp}}$ gives 195 information about the repassivation of the material after pitting; i.e., above $E_{r p}$ pits that 196 have initiated will continue to grow and at potentials below $E_{r p}$ pits repassivate. In the 197 present case, the corrosion potential is below $\mathrm{E}_{\mathrm{rp}}$, so pits can repassivate at potentials 198 between $E_{c o r r}$ and $E_{r p}$. 
199 The surfaces of the stainless steel after the tests were examined with the CLSM. The 200 number of pits together with their diameter is considerably greater in the test performed

201 in the most concentrated solution, that is, $\mathrm{Br}^{-}$ions increase the pitting corrosion rate

202 [34]. This result is in agreement with the parameters determined from polarization 203 curves.

\subsection{Influence of passivation potential studied by SECM}

207 Figure 4 shows the 3D maps of the AISI 304 SS surface biased at three different 208 potentials among the passive range, i.e. $0,0.1$ and $0.2 \mathrm{~V}_{\mathrm{Ag} / \mathrm{AgCl}}$ whereas the tip potential 209 was set at $-0.7 \mathrm{~V}_{\mathrm{Ag} / \mathrm{AgCl}}$. Figure 4(a) and (b) represent the evolution of the current at the

210 UME tip in the $0.2 \mathrm{M}$ and $0.6 \mathrm{M} \mathrm{LiBr}$ solutions, respectively. The images correspond to $2112000 \mu \mathrm{m} \times 2000 \mu \mathrm{m}$ in $X$ and $Y$ directions. The plot in Figure 4(a) shows that current 212 values determined at the UME tip are higher (in absolute value), compared to those 213 obtained in the most concentrated $\mathrm{LiBr}$ solution (Figure 4(b)). This result seems to be 214 reasonable since the solubility of oxygen diminishes with salinity (the experimental

215 Henry's Law constants for oxygen in the $0.2 \mathrm{M}$ and $0.6 \mathrm{M} \mathrm{LiBr}$ solutions at atmospheric 216 pressure and $25^{\circ} \mathrm{C}$ are $4.54 \cdot 10^{4}$ atm. and $4.76 \cdot 10^{4}$ atm., respectively) [35]. Additionally,

217 the current at the UME tip follows the same tendency with the applied potential in both 218 concentrations; that is, it increases (in absolute value) as the potential is raised. The 219 same tendency of the tip current obtained in both concentrations represents the 220 reproducibility of the tests.

221 Passive films generally form as bilayers, with a highly disordered "barrier" layer 222 adjacent to the metal and an outer film consisting of a precipitated phase that may 223 incorporate anions and/or cations from the solution. Passivity is mainly attributed to the 
224 barrier layer [36]. The passive films formed on stainless steels are considered highly

225 doped semiconductors with dopant or defect densities [4, 37-39]. The protectiveness of

226 the passive film is affected by the density of dopants or charge carriers and the latter is

227 dependent on the applied potential in the passive domain. The passive film thus

228 constitutes a barrier layer to ion transfer but not to electron transfer. Any redox electron

229 transfer reaction is therefore allowed to occur on the passive film-covered metal surface

230 just like on the metal surface without any film [40]. In fact, it is well known that the

231 reduction of oxygen takes place in the formation of the passive film as cathodic reaction

232 [41-43]. In this way, during the formation of the passive films, i.e. at the applied

233 potentials shown in Figure 4, there should be a competition between the oxygen

234 consumed in the corresponding cathodic reaction at the passive film on the stainless

235 steel and at the UME tip. Taking into consideration that higher potentials promote an

236 increase in the redox reaction rates [44, 45], a gradual decrease (in absolute value) in the

237 tip current value with the applied potential, due to an increase of the oxygen reaction in

238 the cathodic regions of the passive film, should be shown in Figure 4. However, Figure

2394 shows an opposite trend, that is, as the applied potential in the passive domain is

240 increased, the current at the UME tip increases in absolute value. Therefore, the increase

241 in absolute value of the tip current with the applied potential cannot be explained due to

242 the presence of oxygen. Hence, other redox species that are influenced by the applied

243 potential are interfering in the tip current. According to the Point Defect Model (PDM)

$244[36,46]$ the transmission of ions through the barrier layer occurs by vacancy motion,

245 due to the preponderance of Schottky defects. Then, the following reactions may occur

246 at the metal/film and film/solution interfaces [36, 47, 48]:

247 - Reactions at the metal/film interface: 
$m+V_{M}^{X^{\prime}} \stackrel{k_{1}}{\longrightarrow} M_{M}+v_{m}+X e^{-}$

$m \stackrel{k_{2}}{\longrightarrow} M_{i}^{X+}+v_{m}+X e^{-}$

$m \stackrel{k_{3}}{\longrightarrow} M_{M}+\frac{X}{2} V_{o}^{\bullet}+X e^{-}$

249 - Reactions at the film/solution interface:

$$
\begin{aligned}
& M_{M} \stackrel{k_{4}}{\longrightarrow} M^{\delta+}+V_{M}^{X^{\prime}}+(\delta-X) e^{-} \\
& M_{i}^{X+} \stackrel{k_{5}}{\longrightarrow} M^{\delta+}+(\delta-X) e^{-} \\
& V_{O}^{\bullet \bullet}+H_{2} O \stackrel{k_{6}}{\longrightarrow} O_{O}+2 H^{+} \\
& M O_{X / 2}+X H^{+} \stackrel{k_{7}}{\longrightarrow} M^{\delta+}+\frac{X}{2} H_{2} O+(\delta-X) e^{-}
\end{aligned}
$$

251 where $m$ is a metal atom, $V_{M}{ }^{X}$ is a cation vacancy in the passive film, $M_{i}^{X+}$ is an 252 interstitial cation, $M_{M}$ is a metal cation in a cation site of the film, $v_{M}$ is a cation vacancy 253 in metal phase, $V_{o}^{\bullet \bullet}$ is an anion vacancy in the passive film, $O_{O}$ is an oxygen ion in the 254 passive film, $M^{+\delta}$ is a metallic cation in the electrolyte and $M O_{X / 2}$ is the stoichiometric passive film ( $X$ is the oxidation state of the cations in the passive film and $\delta$ is the oxidation state of the cations in the solution).

258 As the applied potential on the passive region of the stainless steel is increased, the rate of the redox reactions is affected. Therefore, according to the reactions proposed in the

260 PDM, oxidation equations 2 to 6 and 8 could take place. However, in the system 261 proposed in this research, the charge of the cations in the oxides that form the passive 
262 film $(X)$ is equal to the charge of these cations in the solution $(\delta)$, hence only reactions

263 shown in equations 2 to 4 occurring at the metal/film interface involve an exchange of

264 electrons. The rate of the aforementioned redox reactions will increase as the applied

265 potential is also increased $[44,45]$. Thus, increasing the potential increases the rates of

266 formation of metallic cations in the film $\left(M_{M}\right.$, in equations 2 and 4$)$ and of interstitial

267 cations $\left(M_{i}^{X+}\right.$ in equation 3). Furthermore, when the presence of these species in the

268 passive film increases, the rate of the reactions taking place at the film/solution interface

269 can be enhanced (equations 5 and 6), leading therefore to the formation of metallic

270 cations in the solution $\left(M^{\delta+}\right)$. As the number of metallic cations ejected from the metal

271 to the solution increases, the current at the UME tip might also increase (in absolute

272 value) and at its applied potential $\left(-0.7 \mathrm{~V}_{\mathrm{Ag} / \mathrm{AgCl}}=-0.495 \mathrm{~V}_{\mathrm{NHE}}\right)$, the cations that reach

273 the tip may be reduced.

275 The species that are present in the studied system are oxygen, water, bromide anions $276\left(\mathrm{Br}^{-}\right)$and lithium cations $\left(\mathrm{Li}^{+}\right)$of the electrolyte and those cations coming from the 277 passive film of the stainless steel. The $\mathrm{Br}^{-}$anions cannot be further reduced and the $\mathrm{Li}^{+}$ 278 cannot be reduced at the potential applied at the UME tip $\left(\mathrm{E}_{\mathrm{Li}+\mathrm{Li}}^{0}=-3.05 \mathrm{~V}_{\mathrm{NHE}}\right)$. 279 Moreover, neither water may be reduced to $\mathrm{H}_{2}\left(\mathrm{E}_{\mathrm{H} 2 \mathrm{O}+\mathrm{H} 2}^{0}=-0.83 \mathrm{~V}_{\mathrm{NHE}}\right)$. Nevertheless, 280 as it was previously mentioned, oxygen in neutral or alkaline media might be reduced to

$281 \mathrm{OH}^{-}\left(\mathrm{E}_{\mathrm{O} 2 / \mathrm{OH}-}^{0}=0.40 \mathrm{~V}_{\mathrm{NHE}}\right)$, but oxygen reduction cannot explain the results shown in

282 Figure 4, as mentioned above. On the other hand, the main elements present in the AISI 283304 (iron, chromium and nickel), may be in their different oxidation states depending on 284 the applied potential among the passive region ( 0 to $0.2 \mathrm{~V}_{\mathrm{Ag} / \mathrm{AgCl}}=0.21-0.41 \mathrm{~V}_{\mathrm{NHE}}$ ).

285 Therefore, all the reactions with a standard electrode potential (reduction potential) 286 lower than the applied passive potential might take place in the oxidation direction, that 
is, the reduced form of the pair with lower potential will be oxidized. According to the

288 standard electrode potentials, the iron, chromium and nickel species are stable at 0.21 -

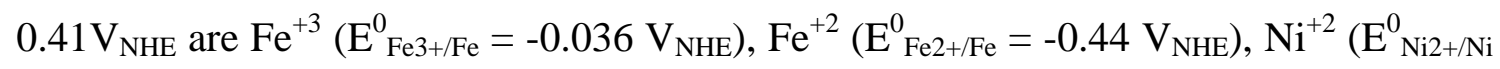

$\left.290=-0.23 \mathrm{~V}_{\mathrm{NHE}}\right)$ and $\mathrm{Cr}^{+3}\left(\mathrm{E}_{\mathrm{Cr} 3+/ \mathrm{Cr}}^{0}=-0.73 \mathrm{~V}_{\mathrm{NHE}}\right)$. Thus, from a thermodynamic point of

291 view the cations ejected from the passive film formed on the stainless steel in our study

292 may be $\mathrm{Fe}^{+2}, \mathrm{Fe}^{+3}, \mathrm{Ni}^{+2}$ and $\mathrm{Cr}^{+3}$. Then, in order to relate the current at UME tip with

293 the reduction of some species, it is necessary to know which of the aforementioned

294 cations would be reduced at $-0.7 \mathrm{~V}_{\mathrm{Ag} / \mathrm{AgCl}}=-0.495 \mathrm{~V}_{\mathrm{NHE}}$, i.e. the potential held at the

295 UME tip. Any reduction reaction with a standard electrode potential higher than -0.495

$296 \mathrm{~V}_{\text {NHE }}$ might take place in our system. The following reactions may occur:

297

$$
\begin{aligned}
& \mathrm{Fe}^{2+}+2 \mathrm{e}^{-} \rightarrow \mathrm{Fe}\left(E_{\mathrm{Fe} 2+/ \mathrm{Fe}}^{0}=-0.44 \mathrm{~V}_{\mathrm{NHE}}\right) \\
& \mathrm{Ni}^{2+}+2 \mathrm{e}^{-} \rightarrow \mathrm{Ni}\left(E_{\mathrm{Ni2}+/ \mathrm{Ni}}^{0}=-0.23 \mathrm{~V}_{\mathrm{NHE}}\right) \\
& \mathrm{Fe}^{3+}+3 \mathrm{e}^{-} \rightarrow \mathrm{Fe}\left(E_{\mathrm{Fe} 3+/ \mathrm{Fe}}^{0}=-0.036 \mathrm{~V}_{\mathrm{NHE}}\right) \\
& \mathrm{Fe}^{3+}+\mathrm{e}^{-} \rightarrow \mathrm{Fe}^{2+}\left(E_{\mathrm{Fe} 3+/ \mathrm{Fe} 2+}^{0}=0.77 \mathrm{~V}_{\mathrm{NHE}}\right)
\end{aligned}
$$

299 Note that in order to reduce $\mathrm{Cr}^{3+}$ to metallic $\mathrm{Cr}$, more negative potentials are needed $300 \quad\left(-0.73 \mathrm{~V}_{\mathrm{NHE}}\right)$.

301 According to the literature [7, 8, 49] nickel has not been found in the composition of 302 AISI 304 or AISI 316 SS passive films. Hence, the possible reactions at the UME tip 303 (apart from the reduction of $\mathrm{O}_{2}$ to $\mathrm{OH}^{-}$, which is always present in our system, see

304 Figure 1) are those involving iron species $\left(\mathrm{Fe}^{+2}\right.$ and $\left.\mathrm{Fe}^{+3}\right)$. In this way, a logical 305 explanation of the tendency observed in Figure 4 (i.e., the current of the UME tip 306 increases in absolute value as the potential also increases), might be the higher amount of iron cations ejected from the passive film and available at the UME tip due to an 
308 increase in the applied potential. Then, at higher potentials more cations are reduced to

309 iron (equations 8 and 10) at the UME tip which is held at

$310-0.7 \mathrm{~V}_{\mathrm{Ag} / \mathrm{AgCl}}[14]$

311

312 3.3. SECM imaging of active pitting corrosion and repassivation

314 To study the initiation and formation of stable pits on the surface of the AISI 304 SS in

$3150.2 \mathrm{M} \mathrm{LiBr}$ solution, different potentials were selected and applied to the substrate (in

316 the passive region but close to the value of $E_{p}$ determined from polarization curves in

317 Figure 3). The lowest potential at which a stable pit appeared was $0.45 \mathrm{~V}_{\mathrm{Ag} / \mathrm{AgCl}}$, so the

318 sample was biased at this value. After the appearance of the first stable pit, different line

319 scans of $3000 \mu \mathrm{m}$ each were performed just above the pit, setting the UME tip potential

320 at $-0.7 \mathrm{~V}_{\mathrm{Ag} / \mathrm{AgCl}}$. To perform these experiments, a test solution of $0.2 \mathrm{M} \mathrm{LiBr}$ has been

321 chosen instead of $0.6 \mathrm{M} \mathrm{LiBr}$ to minimize the appearance of pits on the electrode

322 surface when imposing a potential close to $E_{p}$.

324 Figure 5 shows the line scans at different polarization times. It can be observed that, 325 regardless of the polarization time, the currents recorded when the tip passed just over 326 the center of the pit $(X=1500 \mu \mathrm{m})$ were significantly higher (in absolute value) than 327 the currents measured over the areas covered with an undamaged passive film. Souto et 328 al $[25,26]$, working with polymer-coated carbon steel plates, also observed an increase 329 in the current measured at the tip when it passed over a circular defect artificially 330 produced in the organic coating. They explained these results in terms of an 331 enhancement of the amount of soluble oxygen available from the electrolyte volume 332 inside the hole, since the substrate surface was no longer obstructing the diffusion of 
oxygen from the bulk. Consequently, the currents measured at the UME tip over the defect were of the same order of magnitude as that recorded in the bulk solution for oxygen reduction. In the present case, however, currents recorded at the tip near the active pit were far more negative than those observed in the bulk solution associated with the reduction of oxygen at the UME tip (which are of the order of $-2 \mathrm{nA}$, see

\section{Figure 2).}

340 On the other hand, since a process of active corrosion was taking place inside the pit

341 (the current of the substrate increased drastically just before the appearance of the stable 342 pit), a redox competition for dissolved oxygen could be expected to occur inside the pit 343 between the UME tip and the bare steel surface. According to Souto et al $[21,25,26]$,

344 the concentration of oxygen available to be reduced at the tip will decrease near a 345 corroding surface, such as inside an active pit, due to the appearance of cathodic sites 346 where oxygen can be consumed. Assuming that it is the $\mathrm{O}_{2}$ reduction reaction that is 347 taking place at the tip, a decrease in the amount of oxygen available at the tip would 348 lead to a decrease (in absolute value) in the tip current. However, such a decrease in the 349 tip current near the active pit with respect to the background current is not observed in 350 Figure 5.

352 Inside a stable pit the characteristics of the electrolyte are different from those in bulk 353 solution [31]. The local environment becomes enriched in metal cations and anionic 354 species such as bromides or chlorides, and the $\mathrm{pH}$ is lower owing to cation hydrolysis. 355 This fact makes pitting autocatalytic, that is, once a pit becomes stable, it grows at an ever-increasing rate without any external stimulus [2, 31]. During active corrosion of

357 iron and stainless steels (such as AISI $304 \mathrm{SS}$ ), $\mathrm{Fe}^{2+}$ cations are produced inside the pits 
$358[11,14,24,50]$. Other cations such as $\mathrm{Cr}^{3+}$ and $\mathrm{Ni}^{2+}$ can also be produced inside active

359 pits formed on stainless steels $[28,51]$. The high currents measured at the UME tip

360 when it was located just over the pit suggest an active corrosion process inside the pit

361 releasing metal cations and a subsequent reduction of those cations at the UME tip [11,

362 14], which was biased at $-0.7 \mathrm{~V}_{\mathrm{Ag} / \mathrm{AgCl}}$. Protons may also be simultaneously reduced at

363 the tip [14, 52].

364

365 To confirm the explanations given above concerning the reduction process taking place

366 at the tip, Figure 6 shows a cyclic voltammogram taken while the tip was positioned

367 near the active corrosion pit. Comparing the voltammogram after corrosion with that

368 recorded in the solution bulk before corrosion (initial in Figure 6), it can be clearly

369 observed that cathodic currents greatly increased after the corrosion process. This result

370 indicates the presence of high amounts of other reducible species (metal cations) apart

371 from oxygen.

372

373 It can be observed from Figure 5(a) that at short polarization times the tip current

374 reached very negative and approximately constant values, but it started decreasing after

37570 seconds. This behavior can be explained taking into account the precipitation of a

376 salt film on the pit surface $[31,51,53,54]$. The high cathodic currents recorded at short

377 polarization times imply a very high metal dissolution rate (in fact, higher than the

378 diffusion rate of cations from the pit towards the UME tip) leading to an increase in the

379 ionic concentration inside the pit and to eventually reaching supersaturation conditions

$380[31,51]$. This salt layer decreased metal dissolution since it acted as a diffusion barrier

381 and hence the process of pit growth became limited by mass transport. 
383 However, at longer polarization times (from 210 seconds on), the tip current began to increase again (Figure 5(b)) although it never reached values as high as those measured at the beginning of the test, when metal dissolution was very intense. Figure 7 compares the values of the tip current measured just over the active pit at $X=1500 \mu \mathrm{m}$

387 at different polarization times. It can be observed that $\mathrm{I}_{\text {pit }}$ values were very high in the beginning (in absolute value), indicating a very fast dissolution inside the active pit which led to an increase in the concentration of metal cations inside the pit (A in Figure 7) $[31,51]$. Eventually, supersaturation conditions were reached and a solid salt layer

391 formed on the pit surface, leading to a considerable decrease in the tip current over the 392 pit (B in Figure 7) [31, 51]. After the sudden drop in $\mathrm{I}_{\mathrm{pit}}$ due to the precipitation of the salt film on the pit surface, the current value increased again following a linear tendency with time ( $\mathrm{C}$ in Figure 7). This displacement of current towards higher values (in absolute value) with increasing polarization time is consistent with an active process of corrosion taking place inside the pit and is directly related to pit propagation [23]. Moreover, the previous results imply that after 210 seconds of active pitting corrosion, the salt layer formed on the pit surface no longer acted as a diffusion barrier, since a continuous increase in the release of metallic cations from the active pit and their subsequent reduction at the UME tip was observed.

401

402 It is worth mentioning that an increase in the background current with increasing 403 polarization times can be observed in Figure 5, which is associated with the 404 accumulation and slow diffusion of metallic cations released from the substrate towards 405 the bulk solution [24, 55]. Hence, at long polarization times, small amounts of these 406 cations can be reduced at the UME tip far from the pit. However, the ratio between the 407 current over the active pit and the background current is very high and it increases with 
immersion time, which indicates that changes in the background current with time are very small compared to the changes of the tip current measured above the active pit.

410

411 Once the growth of the active pit with time has been studied, the next step is to study

412 the repassivation of the pit when stopping potentiostatic polarization. As in the previous

413 case, different line scans were carried out above the repassivating pit, with the tip

414 potential set at $-0.7 \mathrm{~V}_{\mathrm{Ag} / \mathrm{AgCl}}$ and leaving the AISI $304 \mathrm{SS}$ substrate at open circuit

415 potential. Figure 8 shows the line scans at different repassivation time.

417 It can be observed from Figure 8(a) that immediately after stopping polarization the 418 cathodic current measured at the UME tip sharply decreased (in absolute value). After 419 that (Figure 8) the tip current measured above the pit became less negative with 420 repassivation time until it reached approximately constant values along the scan length 421 after 160 seconds. These results reveal a total repassivation of the existing pit, since its 422 propagation ceased completely. Final values of the tip current are slightly higher than 423 those recorded before the onset of pitting corrosion on the substrate at $0.45 \mathrm{~V}_{\mathrm{Ag} / \mathrm{AgCl}}$. As 424 it has been mentioned above, this difference in background current with time is 425 explained by the gradual accumulation of metallic cations released from the metal 426 substrate.

427 The previous results show that the pit formed on AISI 304 SS under potentiostatic 428 polarization was no longer stable at open circuit potential and stopped propagating. Pit 429 stability depends, among other things, on the maintenance of pit electrolyte composition 430 and pit bottom potential $[31,56]$. If a salt film is formed on the pit bottom, the pit 431 growth rate will be diffusion controlled. Under these circumstances, a decrease in the 432 potential may not lead to repassivation and pits may continue to grow, depending on the 
composition of the pit electrolyte $[31,56]$. The formation of a salt film has been cited

434 above as a likely reason to explain the decrease in the tip current with polarization time 435 after reaching very negative values (Figure 5(a) and Figure 7). However, at longer 436 polarization times (from 210 seconds on) the salt layer no longer influenced pit growth,

437 since the current associated with the cations released from the pit bottom started to 438 increase again (in absolute value) (Figure 7). Therefore, the complete repassivation of 439 the dissolving metal surface at the pit bottom after 160 seconds at open circuit potential 440 indicates that, in the system under study and after some time of potentiostatic pit 441 growth, charge-transfer processes inside the pit played an essential role in its stability.

443 Figure 9 shows the 3D maps of the AISI 304 SS surface obtained at the end of the pit 444 activation process at $0.45 \mathrm{~V}_{\mathrm{Ag} / \mathrm{AgCl}}$ (Figure 9(a)) and at the end of the pit repassivation 445 process at open circuit potential (Figure 9(b)). The images represent $3000 \mu \mathrm{m} \times 2000$ $446 \mu \mathrm{m}$ in $X$ and $Y$ directions, respectively. The plot in Figure 9(a) clearly shows the 447 generation and release of metal cations from a single pit centered in the point $(X=1500$ $448 \mu \mathrm{m} ; \mathrm{Y}=1000 \mu \mathrm{m})$ and reduced afterwards at the UME tip, whose potential was set at $449-0.7 \mathrm{~V}_{\mathrm{Ag} / \mathrm{AgCl}}$. It can be observed from Figure 9(b) that the formation of $\mathrm{Fe}^{2+}$ and other 450 cationic species from the pit was effectively stopped at open circuit potential, since at 451 the point $(\mathrm{X}=1500 \mu \mathrm{m} ; \mathrm{Y}=1000 \mu \mathrm{m})$ the tip current was similar to the background 452 current, indicating a complete repassivation of the pit.

454 Figure 10 shows the 2D image of the pit formed on the AISI 304 SS surface in $0.2 \mathrm{M}$ $455 \mathrm{LiBr}$ solution at $0.45 \mathrm{~V}_{\mathrm{Ag} / \mathrm{AgCl}}$, obtained with a CLSM. In order to visualize the pit 456 morphology and to quantify its depth, two profiles (longitudinal and transversal) were 457 also obtained. It can be observed from the 2D image (Figure 10(a)) that the pit mouth 
had an approximately equiaxed (circular) shape, bounded by facets. According to

459 Newman and Franz, it is possible that this pit grew initially by coalescence from several

460 nucleation points [51]. The average radius of the pit was estimated to be $99.8 \pm 0.7 \mu \mathrm{m}$.

461 It can also be observed from both profiles (Figures $\mathbf{1 0}(\mathbf{b})$ and $\mathbf{1 0}(\mathbf{c})$ ) that the bottom of

462 the pit was not uniform. The average pit depth was $8.0 \pm 0.9 \mu \mathrm{m}$.

463

464 It is evident from the above calculations that the pit radius was far higher than the pit 465 depth, indicating that this pit was not hemispherical but dish-shaped. Some authors 466 working with stainless steels have observed a change in the pit shape from 467 hemispherical to dish-shaped during their growth [57-61]. According to Newman [58, $60,61]$, early pit growth takes place in a hemispherical mode under the remnants of an 469 overhanging passive film; when a pit reaches a critical size, this cover is destroyed and 470 the hemispherical cavity is opened to the bulk solution. Hence, large pits (of the order of 471 several tens or even hundreds of $\mu \mathrm{m}$ in diameter) have been usually found to be dishshaped rather than perfectly hemispherical, because the absence of a pit cover makes the

473 hemispherical shape unstable, resulting in a faster dissolution rate at the pit edges [31, 474 58, 60-63]. These explanations are consistent with the SECM and CLSM observations 475 of the pit formed on AISI 304 SS, which presented a dish-shaped morphology.

476

\section{CONCLUSIONS}

479 An increase in $\mathrm{LiBr}$ concentration from $0.2 \mathrm{M}$ to $0.6 \mathrm{M}$ enhances the passive current 480 density and lowers the pitting potential. 
482 As the applied potential in the passive domain is increased, the current at the UME tip 483 increases in absolute value. This increase can be explained due to the enhancement of 484 metallic cations at the film/solution interface at high potentials, according to the Point

485 Defect Model. As the number of metallic cations ejected from the metal to the solution 486 increases, the current at the UME tip might also increase.

487

488 The tip currents recorded over the center of the pit were significantly higher (in absolute 489 value) than the currents measured over the areas covered with an undamaged passive 490 film. This fact can be explained by an active corrosion process taking place inside the 491 pit, resulting in the release of metal cations and their subsequent reduction at the UME 492 tip.

493

494 The evolution of the tip current over the active pit with polarization time suggested a very high metal dissolution rate during the first 70 seconds and then the precipitation of 496 a salt film on the pit surface after reaching supersaturation conditions. At longer 497 polarization times the tip current began to increase again indicating that an active 498 corrosion process was occurring inside the pit.

499

500 Immediately after stopping polarization the cathodic current measured at the UME tip 501 sharply decreased (in absolute value) and became less negative with repassivation time 502 until it reached approximately constant values. These results reveal a total repassivation 503 of the existing pit.

505 The pit radius was observed to be far higher than the pit depth, indicating that this pit 506 was not hemispherical but dish-shaped. This morphology is consistent with the loss of 
507 the pit cover (a salt layer or the remnants of an overhanging passive film) and the

508 preferential dissolution at the pit edges, leading to a change in pit shape from perfectly

509 hemispherical at the first stages of pit growth to a dish-shaped form at longer times.

510

\section{ACKNOWLEDGEMENTS}

512 The authors would like to express their gratitude to the Generalitat Valenciana for its

513 help in the SECM acquisition (PPC/2011/013) and in the CLSM acquisition

514 (MY08/ISIRM/S/100) and to Dr. Asuncion Jaime for her translation assistance.

515

\section{REFERENCES}

517

518

519

[1] Harold M.Cobb (Ed.), Steel Products Manual: Stainless Steels, Iron \& Steel Society, 1999.

[2] P. A. Schweitzer, Corrosion Engineering Handbook: Fundamentals of Metallic Corrosion, CRC Press, Boca Ratón, FL., 2007.

[3] A. J. Sedriks, Corrosion Resistance of Stainless Steels and Nickel Alloys, in: S.D. Cramer, B.S. Covino, Jr. (Eds.), Corrosion: Fundamentals, Testing and Protection, Vol. 13A, ASM Handbook, ASM International, Materials Park, OH, 2003, p. 697-702.

[4] N. E. Hakiki, S. Boudin, B. Rondot, M. Da Cunha Belo. The electronic structure of passive films formed on stainless steels, Corros. Sci. 37 (1995) 1809-1822. 
[5] T. L. S. Wijesinghe, D. J. Blackwood. Photocurrent and capacitance investigations into the nature of the passive films on austenitic stainless steels, Corros. Sci. 50 (2008) 23-34.

[6] N. E. Hakiki, M. Da Cunha Belo, A. M. P. Simões, M. G. S. Ferreira. Semiconducting Properties of Passive Films Formed on Stainless Steels, J. Electrochem. Soc. 145 (1998) 3821-3829.

[7] I. Olefjord, B. Brox, U. Jelvestam. Surface Composition of Stainless Steels Soc. 132 (1985) 2854-2861.

[8] G. Lothongkum, S. Chaikittisilp, A. W. Lothongkum. XPS investigation of surface films on high Cr-Ni ferritic and austenitic stainless steels, Appl. Surf. Sci. 218 (2003) 203-210. 
[13] S. B. Basame, H. S. White, Scanning Electrochemical Microscopy of Native Titanium Oxide Films. Mapping the Potential Distribution of SpatiallyLocalized Electrochemical Reactions, J. Phys. Chem. 99 (1995) 16430-16435.

553

554

555

556

557

558

559

560

561

562

563

564

565

566

567

568

569

570

571

[14] J. W. Still, D. O. Wipf, Breakdown of the Iron Passive Layer by Use of the Scanning Electrochemical Microscope, J. Electrochem. Soc. 144 (1997) 26572665.

[15] Y. Zhu, D. E. Williams, Scanning Electrochemical Microscopic Observation of a Precursor State to Pitting Corrosion of Stainless Steel, J. Electrochem. Soc. 144 (1997) L43-L45.

[16] S. B. Basame, H. S. White, Scanning electrochemical microscopy: measurement of the current density at microscopic redox-active sites on titanium, J. Phys. Chem. B 102 (1998) 9812-9819.

[17] D. E. Williams, T. F. Mohiuddin, Y. Y. Zhu, Elucidation of a Trigger Mechanism for Pitting Corrosion of Stainless Steels Using Submicron Resolution Scanning Electrochemical and Photoelectrochemical Microscopy, J. Electrochem. Soc. 145 (1998) 2664-2672.

[18] T. E. Lister, P. J. Pinhero, Scanning Electrochemical Microscopy Study of Corrosion Dynamics on Type 304 Stainless Steel, Electrochem. Solid St. 5 (2002) B33-B36.

[19] T. E. Lister, P. J. Pinhero, The effect of localized electric fields on the detection of dissolved sulfur species from Type 304 stainless steel using scanning electrochemical microscopy, Electrochim. Acta 48 (2003) 2371-2378. 
[20] Y. González-García, G. T. Burstein, S. González, R. M. Souto, Imaging metastable pits on austenitic stainless steel in situ at the open-circuit corrosion potential , Electrochem. Commun. 6 (2004) 637-642.

[21] R. M. Souto, Y. González-García, S. González, In situ monitoring of electroactive species by using the scanning electrochemical microscope. Application to the investigation of degradation processes at defective coated metals, Corros. Sci. 47 (2005) 3312-3323.

[22] E. Völker, C. González Inchauspe, E. J. Calvo, Scanning electrochemical microscopy measurement of ferrous ion fluxes during localized corrosion of steel, Electrochem. Commun. 8 (2006) 179-183.

[23] C. Gabrielli, S. Joiret, M. Keddam, H. Perrot, N. Portail, P. Rousseau, V. Vivier, A SECM assisted EQCM study of iron pitting, Electrochim. Acta 52 (2007) 7706-7714.

[24] Y. Yin, L. Niu, M. Lu, W. Guo, S. Chen, In situ characterization of localized corrosion of stainless steel by scanning electrochemical microscope, Appl. Surf. Sci. 255 (2009) 9193-9199.

[25] J. J. Santana, J. González-Guzmán, L. Fernández-Mérida, S. González, R. M. Souto, Visualization of local degradation processes in coated metals by means of scanning electrochemical microscopy in the redox competition mode, Electrochim. Acta 55 (2010) 4488-4494.

[26] Y. González-García, J. J. Santana, J. González-Guzmán, J. Izquierdo, S. González, R. M. Souto, Scanning electrochemical microscopy for the 
investigation of localized degradation processes in coated metals, Prog. Org. Coat. 69 (2010) 110-117.

596

597

598

599

600

601

602

603

604

605

606

607

608

609

610

611

612

613

614

[27] Y. Yuan, L. Li, C. Wang, Y. Zhu, Study of the effects of hydrogen on the pitting processes of X70 carbon steel with SECM, Electrochem. Commun. 12 (2010) 1804-1807.

[28] N. Aouina, F. Balbaud-Célérier, F. Huet, S. Joiret, H. Perrot, F. Rouillard, V. Vivier, Single pit initiation on 316L austenitic stainless steel using scanning electrochemical microscopy, Electrochim. Acta 56 (2011) 8589-8596.

[29] A. J. Bard, M. V. Mirkin (Eds.), Scanning Electrochemical Microscopy, $1^{\text {st }}$. ed., Marcel Dekker, New York, NJ, 2001.

[30] M. Kaneko, H.S. Isaacs, Pitting of stainless steel in bromide, chloride and bromide/chloride solutions, Corros. Sci 42 (2000) 67-78.

[31] G. S. Frankel, Pitting Corrosion of Metals: A Review of the Critical Factors, J. Electrochem. Soc. 145 (1998) 2186-2198.

[32] M. Kaneko, H.S. Isaacs, Effects of molybdenum on the pitting of ferritic- and austenitic-stainless steels in bromide and chloride solutions, Corros. Sci. 44 (2002) 1825-1834.

[33] E. A. Abd EI Meguid, N. A. Mahmoud, Inhibition of Bromide-Pitting Corrosion of Type 904L Stainless Steel, Corrosion 59 (2003) 104-111.

[34] A. Anderko and R. D. Young, Model for Corrosion of Carbon Steel in Lithium Bromide Absorption Refrigeration Systems, Corrosion 56 (2000) 543-555. 
[35] D. S. Chau, B. D. Wood, N. S. Berman, K. J. Kim, Solubility of oxygen in aqueous lithium bromide using electrochemical technique, Int. Comm. Heat Mass Transfer 20 (1993) 643-652.

[36] D. D. Macdonald, The Point Defect Model for the Passive State, J. Electrochem. Soc.139 (1992) 3434-3449.

[37] A. Di Paola, Semiconducting properties of passive films on stainless steels, Electrochim. Acta 34 (1989) 203-210.

[38] N.E. Hakiki, M.F. Montemor, M.G.S. Ferreira, M. da Cunha Belo, Semiconducting properties of thermally grown oxide films on AISI 304 stainless steel, Corros Sci 42 (2000) 687-702.

[39] M.J. Carmezim, A.M. Simões, M.O. Figueiredo, M. Da Cunha Belo, 626

[41] M. S. Venkatraman, I. S. Cole, B. Emmanuel, Corrosion under a porous layer: A porous electrode model and its implications for self-repair, Electrochim alkaline solutions, Electrochim Acta 97 (2013) 192-201. 
[43] S. Gao, C. Dong, H. Luo, K. Xiao, X. Pan, X. Li, Scanning electrochemical microscopy study on the electrochemical behavior of $\mathrm{CrN}$ film formed on 304 stainless steel by magnetron sputtering, Electrochim Acta 114 (2013) 233-241.

[44] G. Lu, J. S. Cooper, P. J. McGinn, SECM imaging of electrocatalytic activity 639 for oxygen reduction reaction on thin film materials, Electrochimica Acta 52 (2007) 5172-5181.

[45] C. Song, J. Zhang, Electrocatalytic Oxygen Reduction Reaction, in: J. Zhang (Ed.), PEM Fuel Cell Electrocatalysts and Catalyst Layers, Ch. 2, Springer, London, 2008, p. 89.

[46] D. D. Macdonald, Passivity - the key to our metals-based civilization, Pure Appl. Chem. 71 (1999) 951-978.

[47] D. D. Macdonald, M. Al Rifaie, G. R. Engelhardt, New Rate Laws for the 647 Growth and Reduction of Passive Films, J. Electrochem. Soc. 148 (2001) B343-B347.

[48] D. D. Macdonald, On the Existence of Our Metals-Based Civilization: I.

[49] C. Marconnet, Y. Wouters, F. Miserque, C. Dagbert, J. P. Petit, A. Galerie, 652 Chemical composition and electronic structure of the passive layer formed on 653 stainless steels in a glucose-oxidase solution D. Féron, Electrochim. Acta 54

654 (2008) 123-132. 
[50] S. Rhode, V. Kain, V.S. Raja, G.J. Abraham, Factors affecting corrosion behavior of inclusion containing stainless steels: A scanning electrochemical microscopic study, Materials Characterization 77 (2013) 109-115

[51] R.C. Newman, E.M. Franz, Growth and repassivation of single corrosion pits 659 in stainless steel, Corrosion 40 (1984) 325-330.

[52] A.M. Simões, A.C. Bastos, M.G. Ferreira, Y. González-García, S. González, 661 R.M. Souto, Use of SVET and SECM to study the galvanic corrosion of an iron-zinc cell, Corros. Sci. 49 (2007) 726-739.

[53] T. R. Beck, R. C. Alkire, Occurrence of Salt Films during Initiation and 664 Growth of Corrosion Pits, J. Electrochem. Soc. 126 (1979) 1662-1666.

665

[54] Richard C. Alkire, Kai P. Wong, The corrosion of single pits on stainless steel 666 in acidic chloride solution, Corros. Sci. 28 (1988) 411-421.

667

[55] A.C. Bastos, A.M. Simões, S. González, Y. González-García, R.M. Souto, 668 Imaging concentration profiles of redox-active species in open-circuit corrosion processes with the scanning electrochemical microscope, Electrochem. Commun. 6 (2004) 1212-1215.

[56] H. Böhni, Localized Corrosion of Passive Metals, in: R. Winston Revie (Ed.), Uhlig's Corrosion Handbook, 2nd ed., Ch. 10, Wiley Interscience, New York, 2000.

[57] R. Leiva-García, J. García-Antón, M.J. Muñoz-Portero Contribution to the 675 elucidation of corrosion initiation through confocal laser scanning microscopy 676 (CLSM), Corros. Sci. 52 (2010) 2133-2142. 
677

678

679

680

681

682

683

684

685

686

687

688

689

690

691

692

693

694

695

696

697

[58] N.J. Laycock, R.C. Newman, Localized dissolution kinetics, salt films and pitting potentials, Corros. Sci. 39 (1997) 1771-1790.

[59] M. H. Moayed, R. C. Newman, The Relationship Between Pit Chemistry and Pit Geometry Near the Critical Pitting Temperature, J. Electrochem. Soc. 153 (2006) B330-B335.

[60] P. Ernst, R.C. Newman, Pit growth studies in stainless steel foils. I. Introduction and pit growth kinetics, Corros. Sci. 44 (2002) 927-941.

[61] P. Ernst, N.J. Laycock, M.H. Moayed, R.C. Newman, The mechanism of lacy cover formation in pitting, Corros. Sci. 39 (1997) 1133-1136.

[62] D. Sun, Y. Jiang, Y. Tang, Q. Xiang, C. Zhong, J. Liao, J. Li, Pitting corrosion behavior of stainless steel in ultrasonic cell, Electrochim. Acta 54 (2009) $1558-1563$.

[63] J. Ren, Y. Zuo, The growth mechanism of pits in $\mathrm{NaCl}$ solution under anodic films on aluminum, Surf. Coat. Tech. 191 (2005) 311-316.

Table captions

Table 1. Electrochemical parameters for AISI 304 SS in both 0.2 and $0.6 \mathrm{M} \mathrm{LiBr}$ solutions, obtained from cyclic polarization curves 
699 Figure 1. Cyclic voltammogram measured at the SECM tip of the AISI 304 SS in the $700 \quad 0.2 \mathrm{M} \mathrm{LiBr}$ solution at $25^{\circ} \mathrm{C}$.

701 Figure 2. Approach curve for the tip polarized at $-0.7 \mathrm{~V}_{\mathrm{Ag} / \mathrm{AgCl}}$ with the AISI $304 \mathrm{SS}$ 702 potential set at $0 \mathrm{~V}$ in the $0.2 \mathrm{M} \mathrm{LiBr}$ solution.

703 Figure 3. Cyclic potentiodynamic polarization curves for AISI 304 in both 0.2 and 0.6 $704 \mathrm{M} \mathrm{LiBr}$ solutions at $25^{\circ} \mathrm{C}$.

705 Figure 4. SECM-3D maps of the AISI 304 SS surface biased at $0,0.1$ and $0.2 \mathrm{~V}_{\mathrm{Ag} / \mathrm{AgCl}}$ 706 in the $0.2 \mathrm{M}(\mathrm{a})$ and $0.6 \mathrm{M}(\mathrm{b}) \mathrm{LiBr}$ solutions.

707 Figure 5. Line scans on a pit formed on the AISI 304 biased at $0.45 \mathrm{~V}_{\mathrm{Ag} / \mathrm{AgCl}}$ in a $0.2 \mathrm{M}$ 708 LiBr solution.

709 Figure 6. Cyclic voltammogram measured near an active corrosion pit and initially at 710 the SECM tip of the AISI $304 \mathrm{SS}$ in the $0.2 \mathrm{M}$ LiBr solution.

711 Figure 7. Current values at the tip current measured on an active pit at different 712 polarization times.

713 Figure 8. Line scans on the AISI 304 maintained at open circuit potential at different 714 repassivation times in the $0.2 \mathrm{M} \mathrm{LiBr}$ solution.

715 Figure 9. SECM-3D maps of the AISI 304 SS surface at the end of the pit activation

716 process at $0.45 \mathrm{~V}_{\mathrm{Ag} / \mathrm{AgCl}}$ (a) and at the end of the pit repassivation process at open circuit 717 potential (b). 
718 Figure 10. CLSM-2D image of a pit formed on the AISI 304 SS surface in the $0.2 \mathrm{M}$

$719 \mathrm{LiBr}$ solution at $0.45 \mathrm{~V}_{\mathrm{Ag} / \mathrm{AgCl}}(\mathrm{a}) . \mathrm{X}$ and $\mathrm{Y}$ depth profiles are shown in (b) and (c), 720 respectively.

721

722

723

724 


\begin{tabular}{|c|c|c|c|c|c|c|}
\hline LiBr Solution & $\begin{array}{c}\mathbf{E}_{\text {corr }} / \mathbf{m V} \mathbf{v s} \\
(\mathbf{A g} / \mathbf{A g C l})\end{array}$ & $\mathbf{i}_{\text {corr }} / \boldsymbol{\mu A} \mathbf{~ c m}^{-2}$ & $\mathbf{i}_{\mathbf{p}} / \boldsymbol{\mu} \mathbf{A} \mathbf{~ c m}^{-2}$ & $\begin{array}{c}\mathbf{E}_{\mathbf{p}} / \mathbf{m V} \mathbf{~ v s} \\
(\mathbf{A g} / \mathbf{A g C l})\end{array}$ & $\begin{array}{c}\mathbf{E}_{\mathbf{r p}} / \mathbf{m V} \mathbf{v s} \\
(\mathbf{A g} / \mathbf{A g C l})\end{array}$ & $\mathbf{i}_{\mathbf{r p}} / \boldsymbol{\mu A} \mathbf{~ c m}^{-2}$ \\
\hline $\mathbf{0 . 2} \mathbf{M}$ & $-124 \pm 7$ & $0.3 \pm 0.1$ & $2.3 \pm 0.2$ & $557 \pm 10$ & $164 \pm 10$ & $5.3 \pm 0.1$ \\
\hline $\mathbf{0 . 6} \mathbf{M}$ & $-147 \pm 10$ & $0.6 \pm 0.1$ & $3.1 \pm 0.2$ & $496 \pm 8$ & $145 \pm 12$ & $6.3 \pm 0.2$ \\
\hline
\end{tabular}




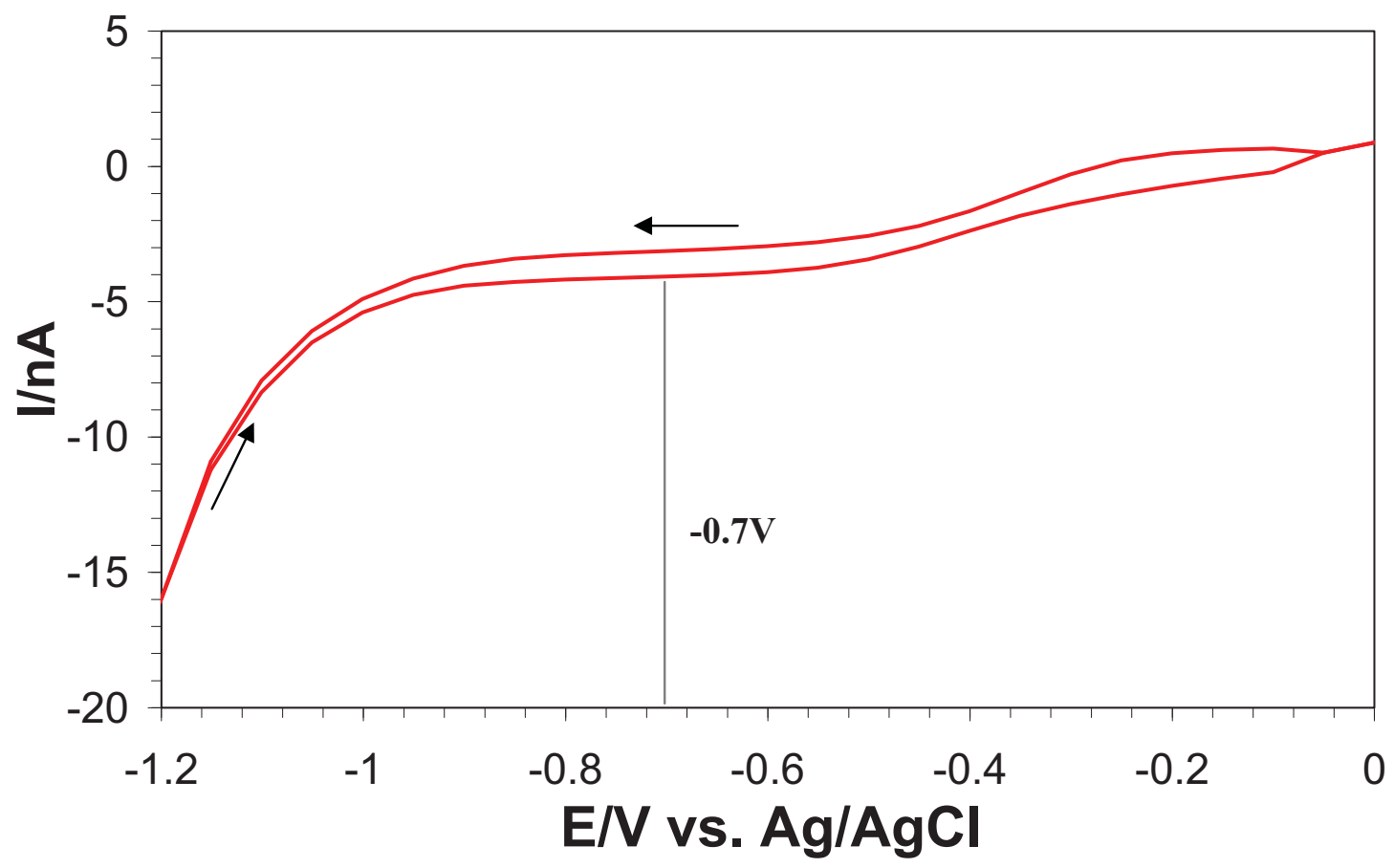




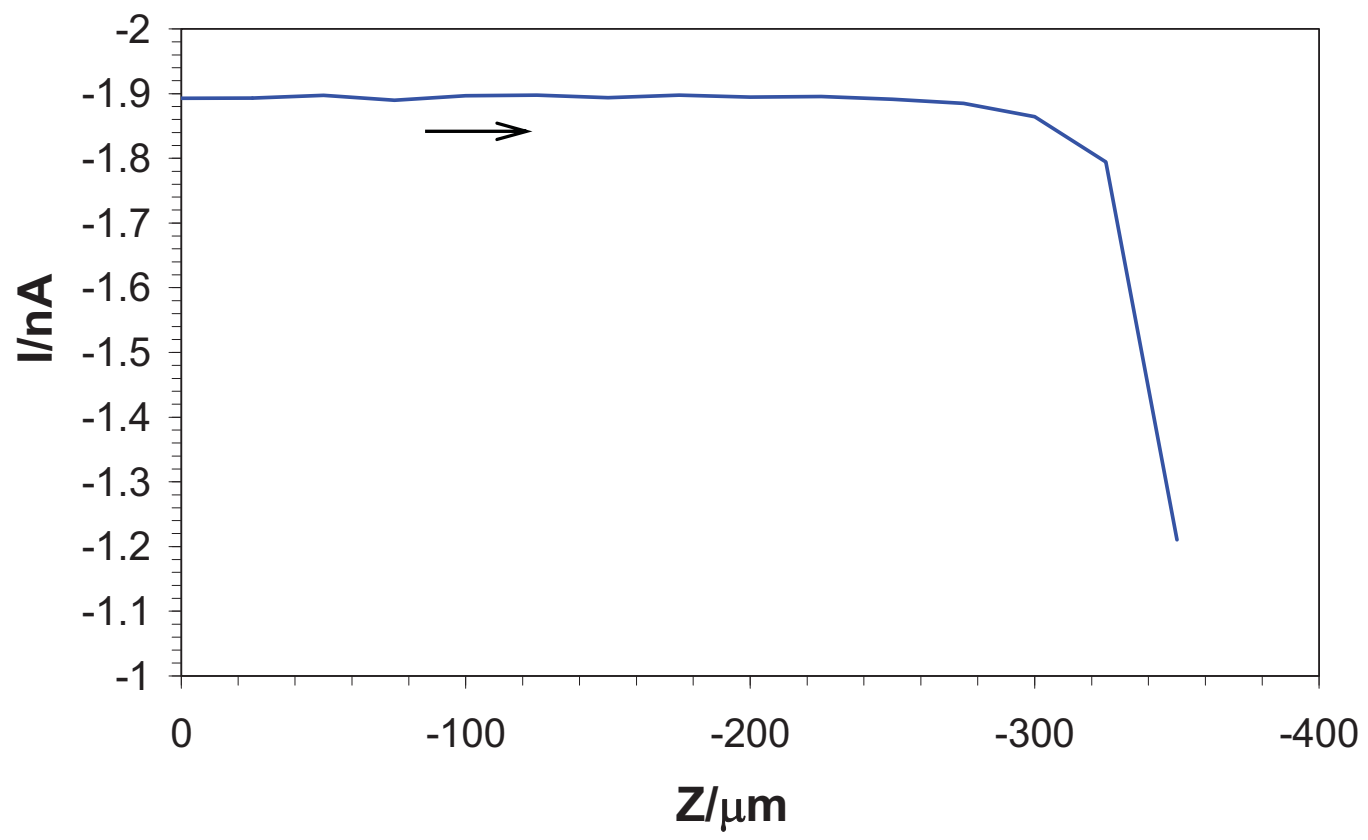




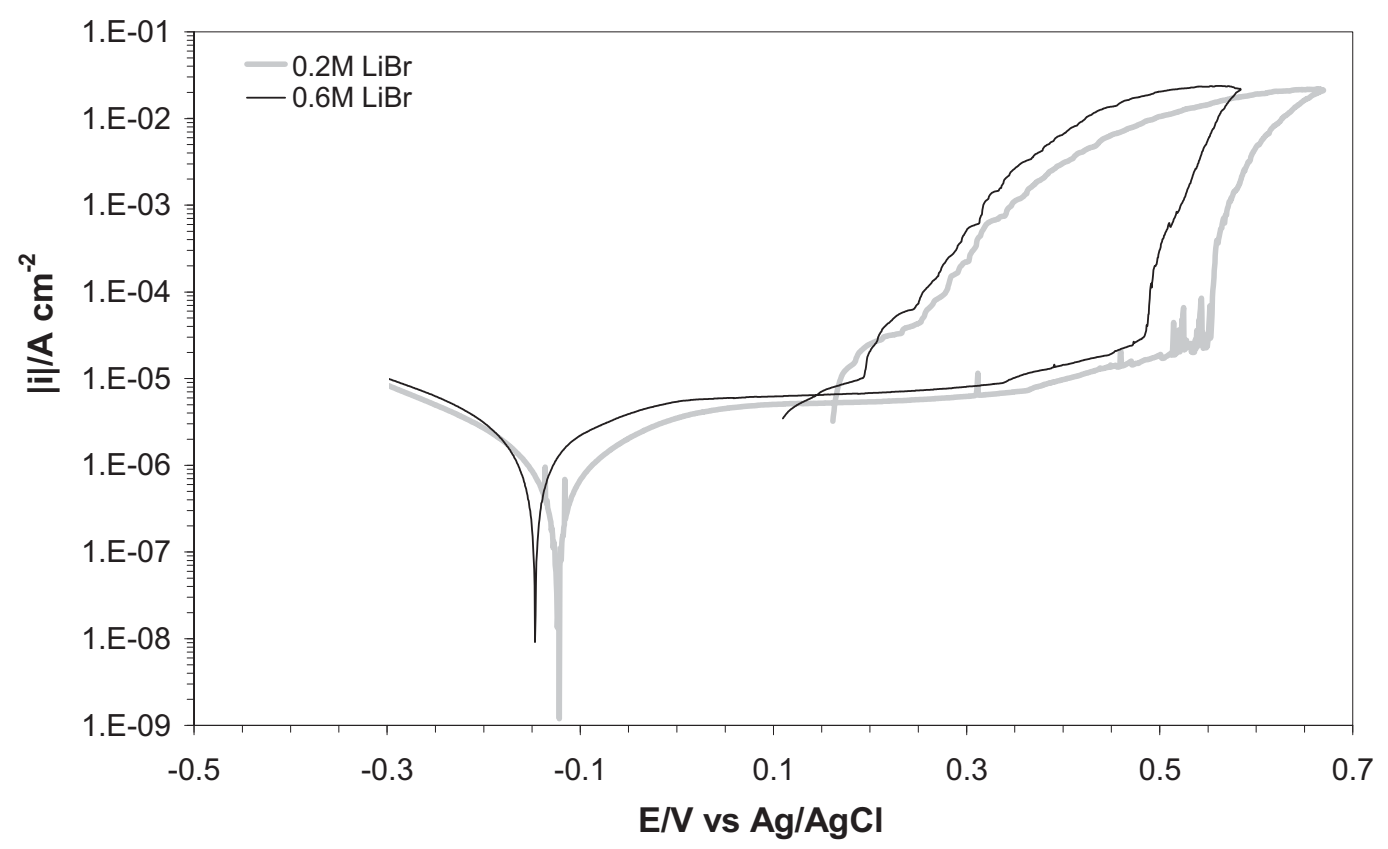


(a) $0.2 \mathrm{M} \mathrm{LiBr}$
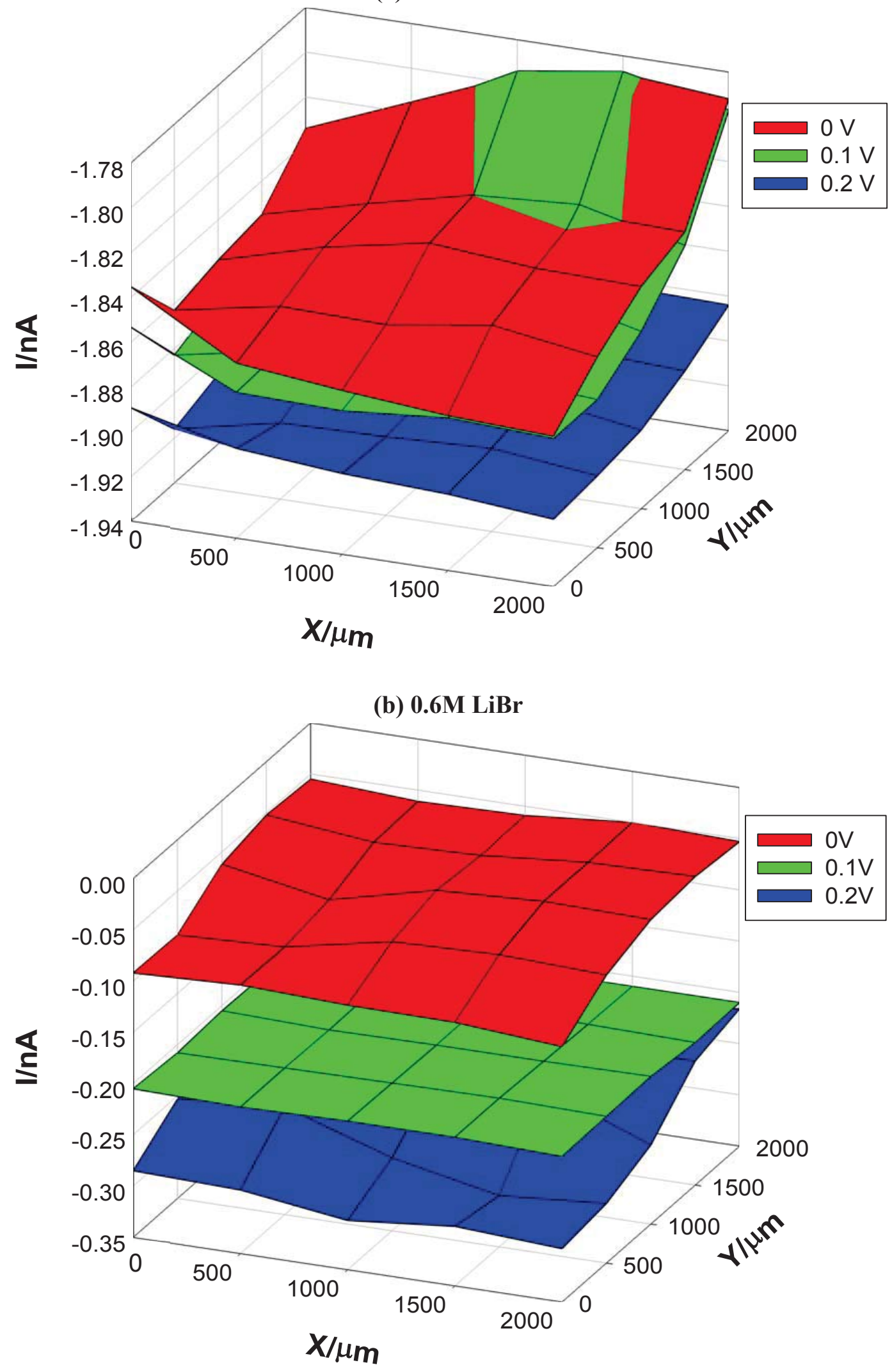

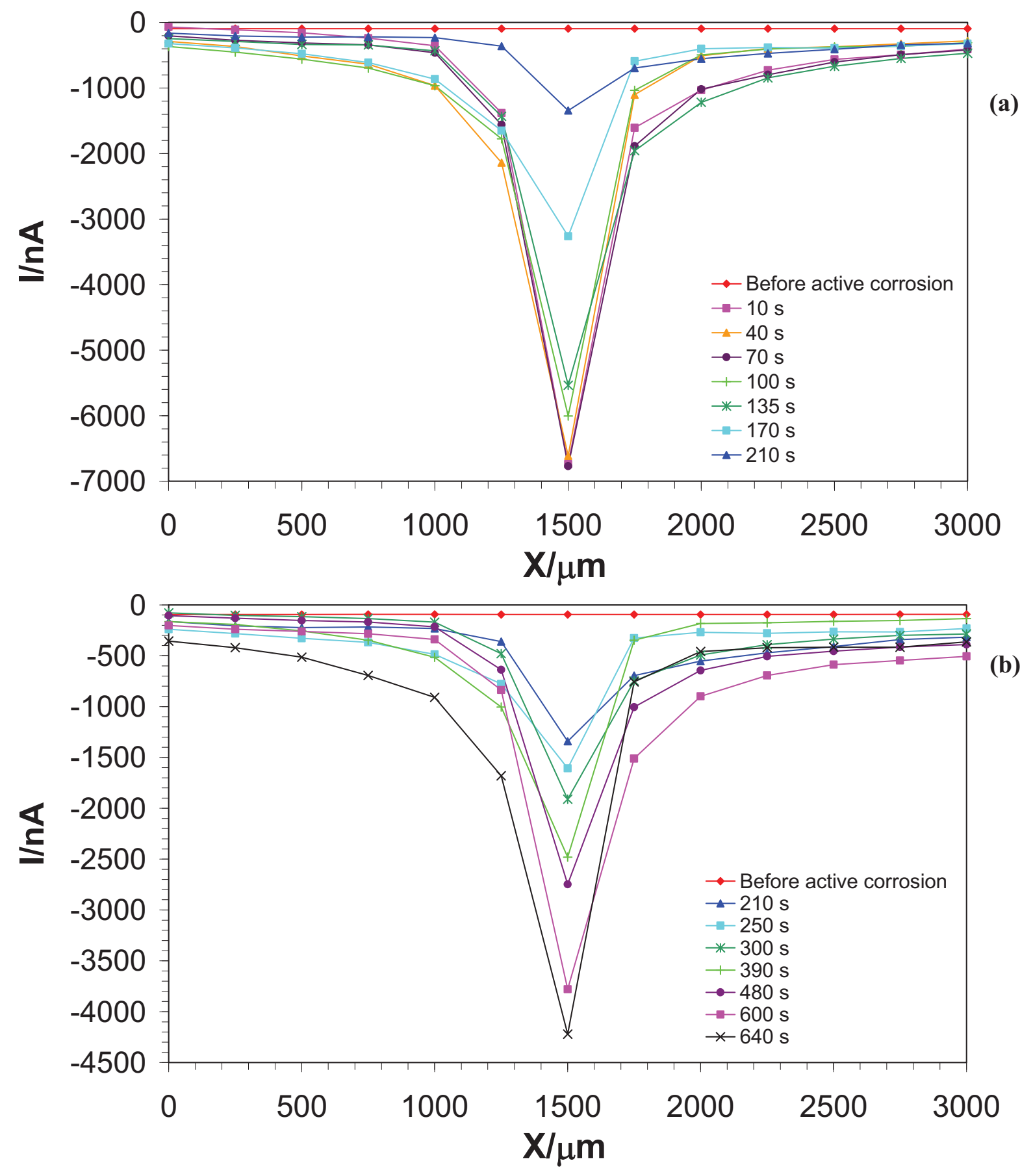


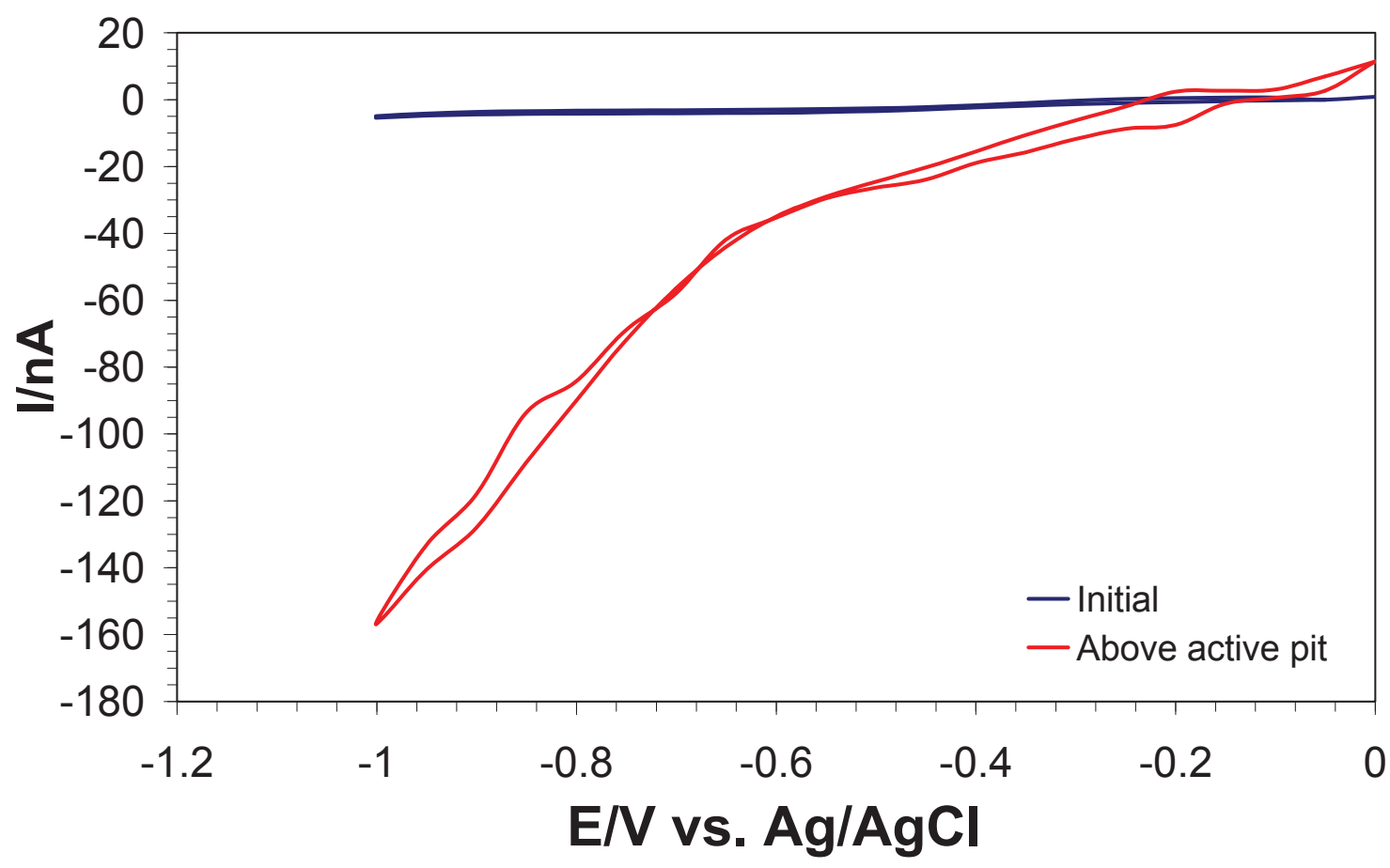




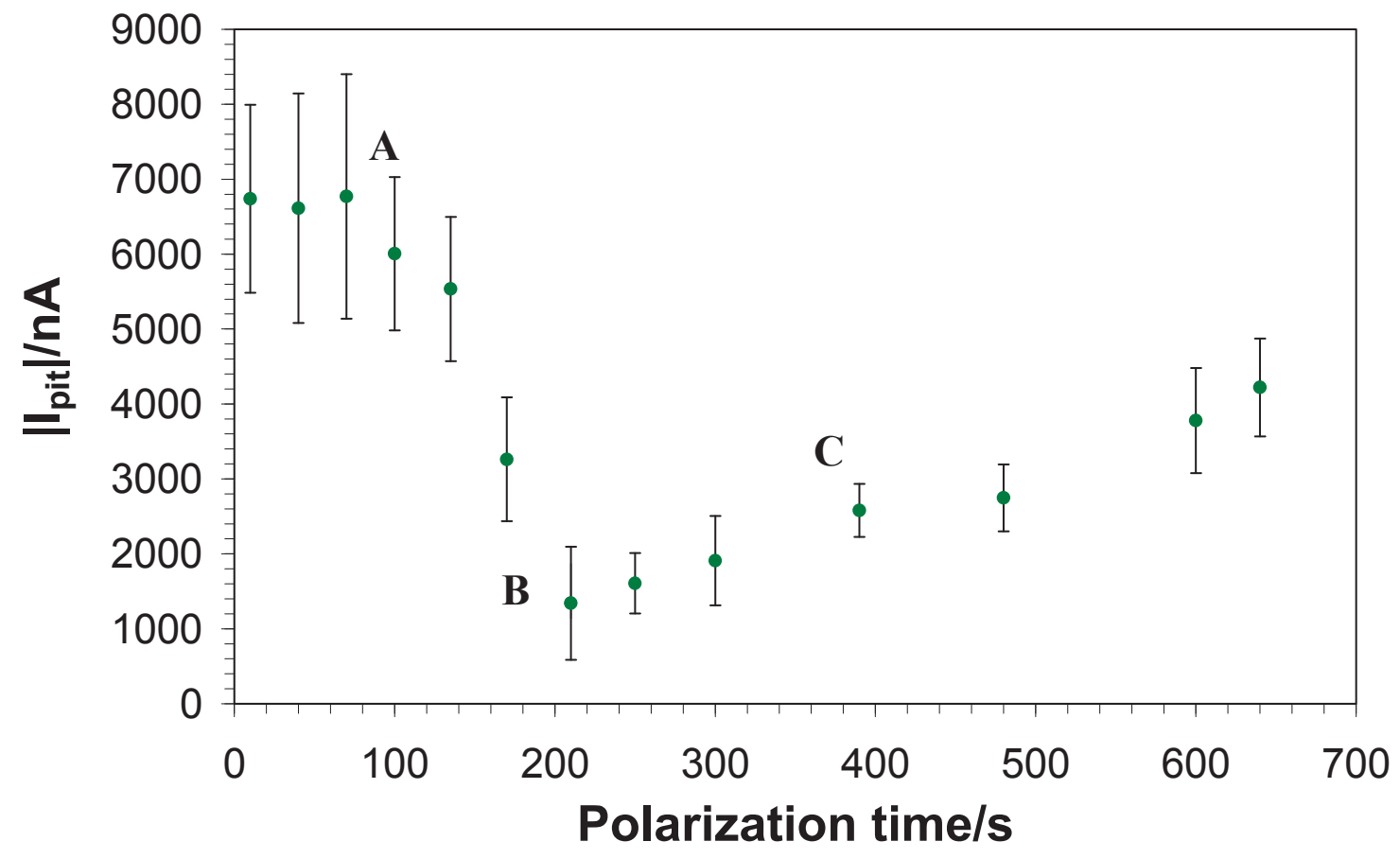



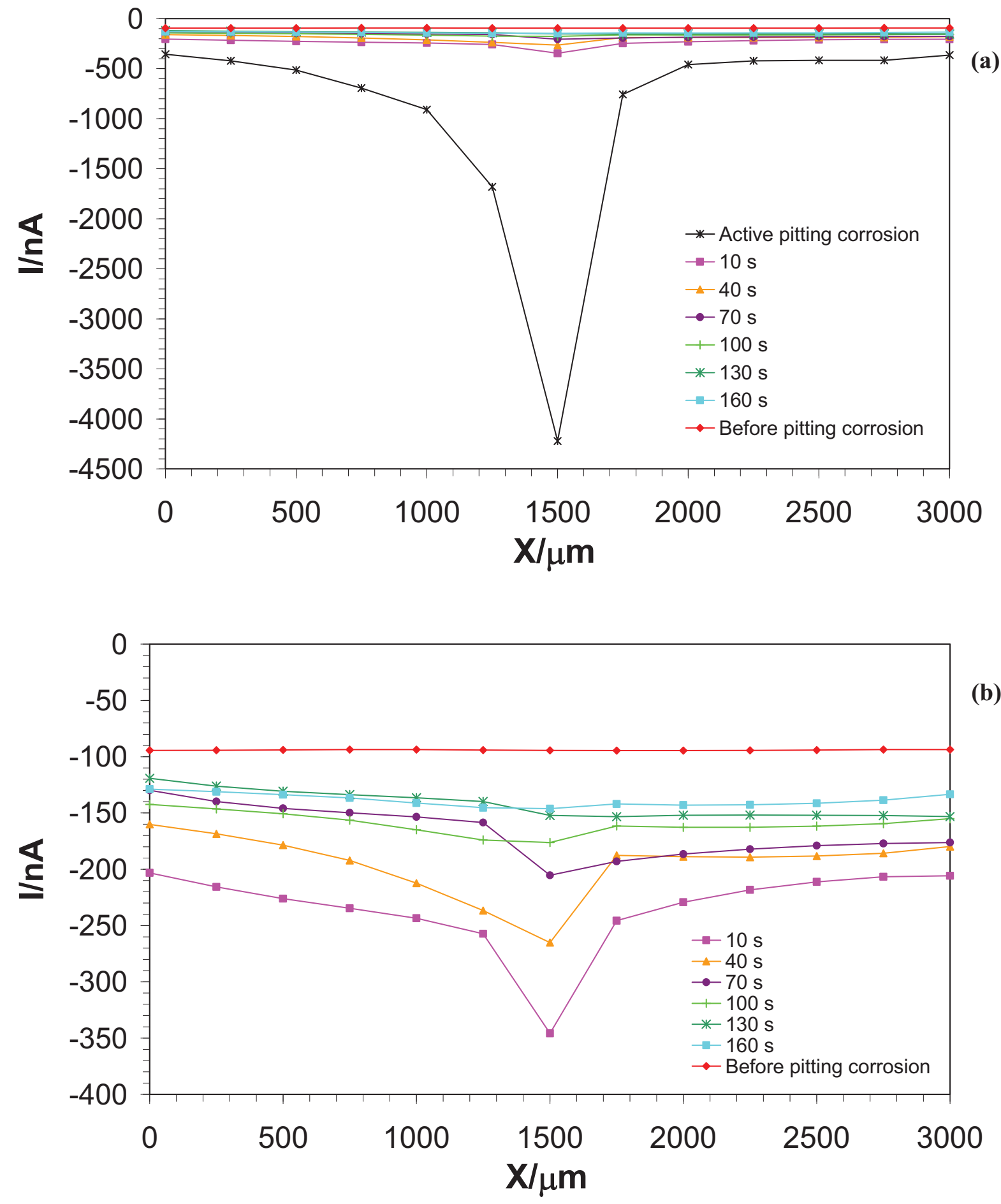

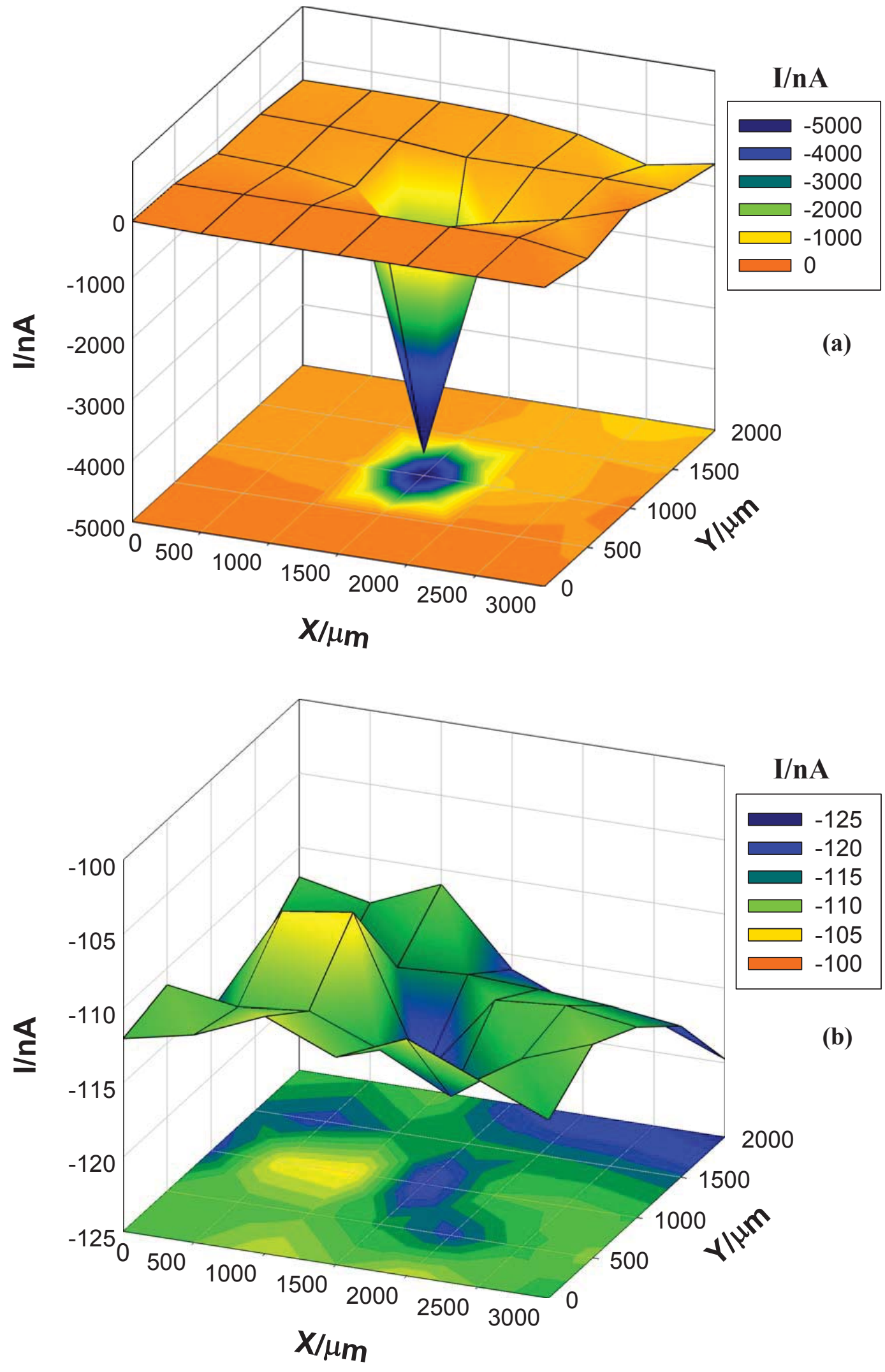


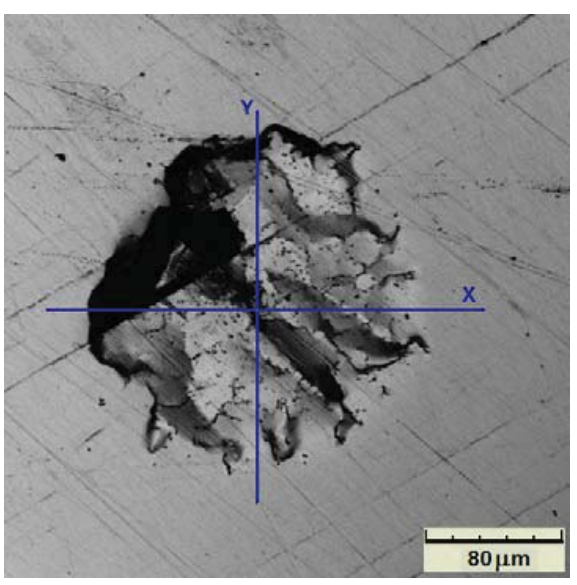

(a)

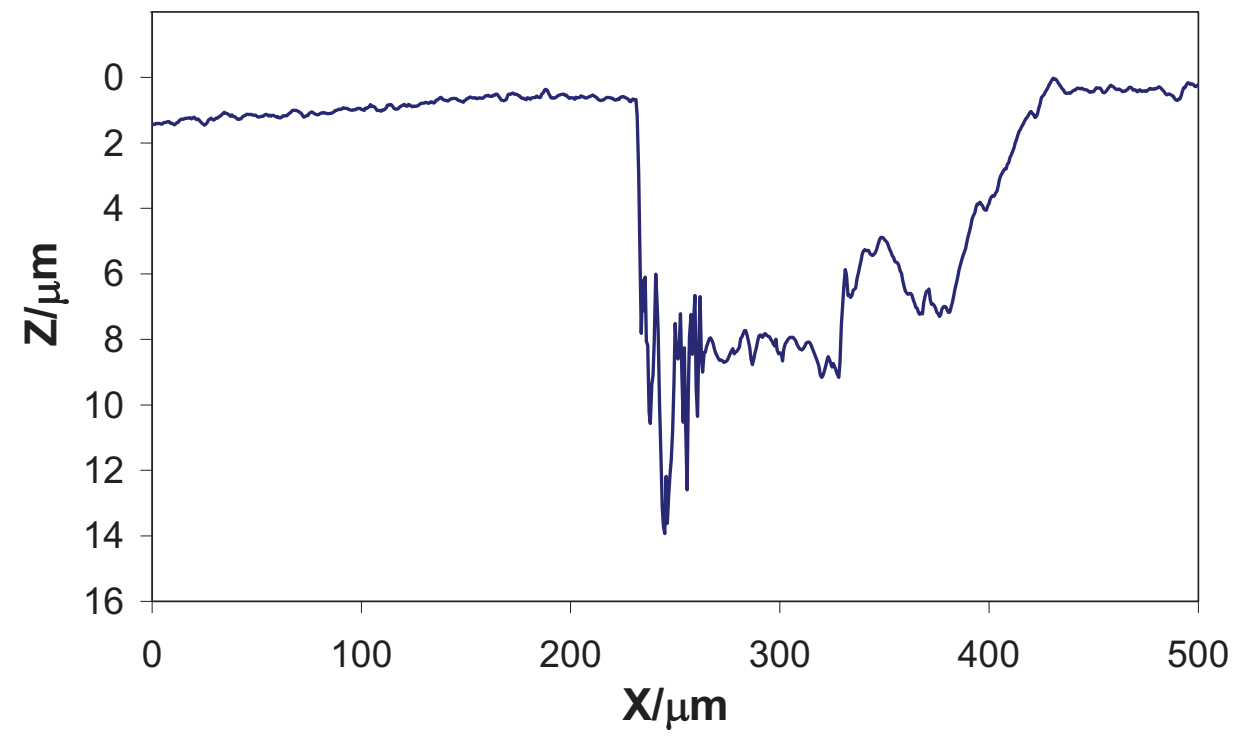

(b)

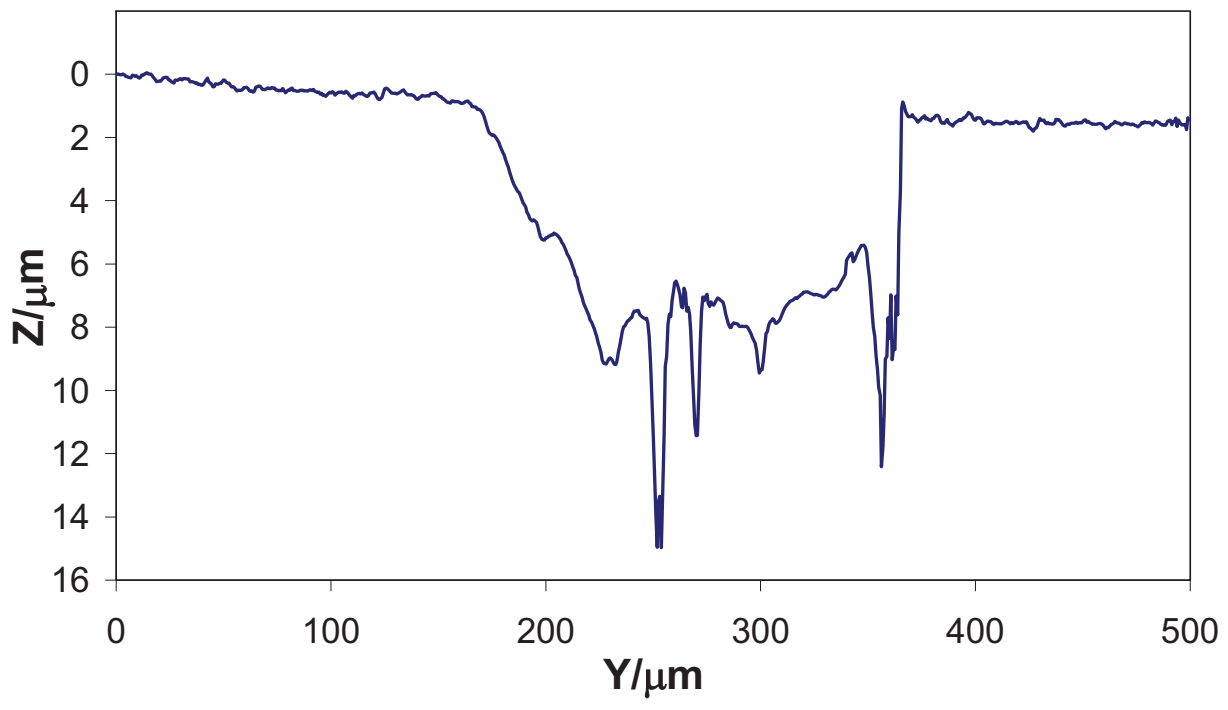

(c) 